\title{
The neuronal insulin sensitizer dicholine succinate reduces stress-induced depressive traits and memory deficit: possible role of insulin-like growth factor 2
}

\author{
Brandon H Cline ${ }^{1}$, Harry WM Steinbusch², Dmitry Malin ${ }^{3,4}$, Alexander V Revishchin ${ }^{4,5}$, Galia V Pavlova ${ }^{5}$,
} Raymond Cespuglio ${ }^{6}$ and Tatyana Strekalova ${ }^{2^{*}}$

\begin{abstract}
Background: A number of epidemiological studies have established a link between insulin resistance and the prevalence of depression. The occurrence of depression was found to precede the onset of diabetes and was hypothesized to be associated with inherited inter-related insufficiency of the peripheral and central insulin receptors. Recently, dicholine succinate, a sensitizer of the neuronal insulin receptor, was shown to stimulate insulin-dependent $\mathrm{H}_{2} \mathrm{O}_{2}$ production of the mitochondrial respiratory chain leading to an enhancement of insulin receptor autophosphorylation in neurons. As such, this mechanism can be a novel target for the elevation of insulin signaling.
\end{abstract}

Results: Administration of DS ( $25 \mathrm{mg} / \mathrm{kg} /$ day, intraperitoneal) in CD1 mice for 7 days prior to the onset of stress procedure, diminished manifestations of anhedonia defined in a sucrose test and behavioral despair in the forced swim test. Treatment with dicholine succinate reduced the anxiety scores of stressed mice in the dark/light box paradigm, precluded stress-induced decreases of long-term contextual memory in the step-down avoidance test and hippocampal gene expression of IGF2.

Conclusions: Our data suggest that dicholine succinate has an antidepressant-like effect, which might be mediated via the up-regulation of hippocampal expression of IGF2, and implicate the neuronal insulin receptor in the pathogenesis of stress-induced depressive syndrome.

Keywords: Dicholine succinate, Insulin-like receptor, Insulin growth factor 2, Hippocampus, Stress-induced anhedonia, Mouse

\section{Background}

Recent epidemiological studies have established a link between diabetes and the prevalence of depression [1,2]. The presence of depressive symptoms is documented in $12.8-29 \%$ of males and $23.8-30.5 \%$ of females with newly diagnosed diabetes $[3,4]$. A positive relationship between insulin resistance and the severity of depressive symptoms has been identified in cross-sectional studies $[5,6]$. Depression in patients with diabetes can result

\footnotetext{
* Correspondence: t.strekalova@maastrichtuniversity.nl

${ }^{2} S$ chool for Mental Health and Neuroscience, Department of Neuroscience, Maastricht University, Universiteitssingel 40, NL 6229 ER, Maastricht, Netherlands

Full list of author information is available at the end of the article
}

from the chronic psychological and medical conditions associated with the disease $[7,8]$; however, the occurrence of depression was found to precede the onset of diabetes which, apart from the behavioral factors and changes in eating habits often accompanying depression, might be associated with inherited inter-related insufficiency of the peripheral and central insulin receptors $[9,10]$.

The neuronal insulin receptors belong to an insulin receptor subfamily of receptor tyrosine kinases (Figure 1A) and many of these receptors have been shown to be involved in multiple mechanisms of synaptic plasticity as well as differentiation and cell survival [11-13]. Analysis 


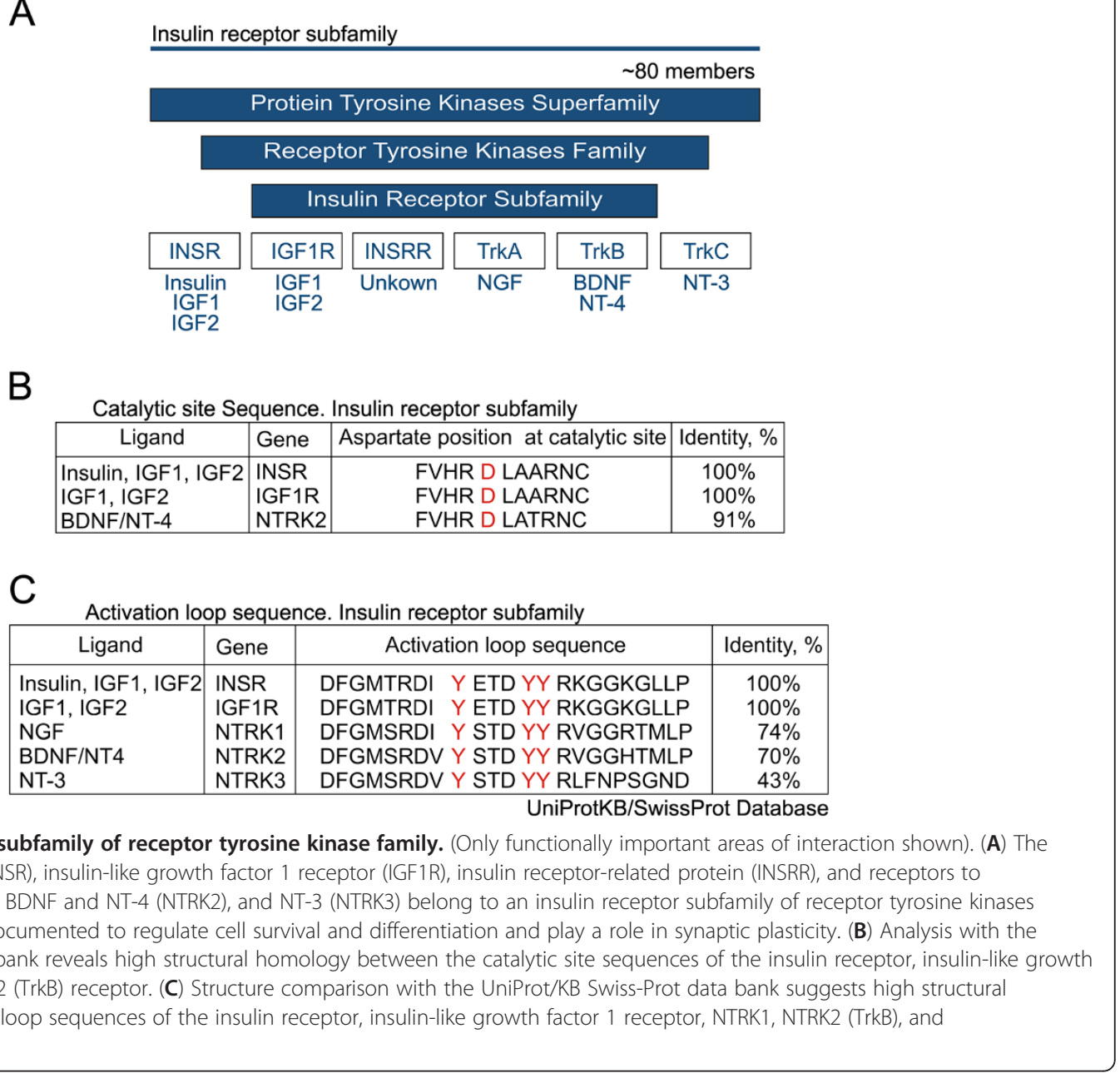

using the UniProt/KB Swiss-Prot data bank revealed high structural homology between the catalytic sites and the activation loops of the insulin receptor and TrkB (Figures 1B, C); it is well known that TrkB manifests a role in the stress response [14-16]. The neuronal insulin receptor is involved in the control of synaptic functions, myelination, plasticity and metabolic processes [17-19] and expresses a robust density in the hippocampus and cerebral cortex [20,21]. Compromised signaling of insulin receptors can result in cognitive deficits [22,23] and insulin signaling has been shown to regulate dopaminemediated neurotransmission in animal models [24], influence the function of norepinephrine and serotonin transporters and consequently extracellular levels of norepinephrine and serotonin [25].

A key regulatory event of neuronal insulin receptor function, the insulin-stimulated autophosphorylation of the insulin receptor kinase at tyrosine residues, was lately found to be dose-dependently activated by dicholine salt of succinic acid (dicholine succinate, DS) suggesting the importance of DS in the mitochondrial biochemical pathway [26-28]. The presence of DS, and other respiratory substrates, stimulates insulindependent $\mathrm{H}_{2} \mathrm{O}_{2}$ production in the mitochondrial respiratory chain leading to an enhancement of insulin receptor autophosphorylation in cerebellar neurons $[28,29]$. As DS elevates the insulin-stimulated non-basal autophosphorylation of the insulin receptor it is considered an important endogenous sensitizer of the neuronal insulin receptor. Several studies demonstrate the biological effects of neuronal insulin receptor stimulation, via the mitochondrial respiratory chain using endogenous and exogenous compounds, and suggest that these effects are implicated in the stress response and the pathogenesis of a depressive-like state. For instance, thiazolidinediones, which act as potent sensitizers of the neuronal insulin receptor, enhance brain glucose utilization though increased neuronal mitochondrial biogenesis [30], decrease neuronal damage [31] and evoke anti-inflammatory effects [32-34]. Rosiglitazone, one of the insulin sensitizers of the thiazolidinedione class, has been found to induce an antidepressant-like effect in the 
tail suspension and forced swim tests in mice [35]. Importantly, this drug and another insulin receptor sensitizer, pioglitazone, were recently reported to be effective for the treatment of a major depressive disorder that was refractory to standard antidepressant treatment and accompanied by insulin resistance [36,37].

Intraperitoneal administration of DS for 7 days at doses of 10 and $25 \mathrm{mg} / \mathrm{kg} /$ day, but not at $1 \mathrm{mg} / \mathrm{kg}$, rescued a $30 \%$-decrease of brain $\mathrm{N}$-acetylaspartate/creatine, a marker of neuronal function and viability, in middleaged C57BL/6 $\mathrm{N}$ mice. In rats, the same treatment at all three doses rescued learning in step-through passive avoidance and a 4-day Morris water maze test; additionally, brain levels of $\mathrm{N}$-acetylaspartate/creatine were also increased which were compromised in a model of chronic cerebral hypoperfusion [28]. Similarly, treatment with the highest dose of DS used in this study, resulted in a recovery of the acquisition of the step-through passive avoidance task and choline acetyltransferase activity which were suppressed in a rat model of beta-amyloid peptide-(25-35)-induced toxicity.

The current study's primary objectives were to evaluate the effects of intraperitoneal administration of DS for 7 days at a dose of $25 \mathrm{mg} / \mathrm{kg} /$ day on the development of depressive syndrome in a mouse chronic stress model and to relate this state to deficits in the step-down inhibitory avoidance learning model $[38,39]$ in addition to anxiety-like behavior in the dark/light paradigm. A secondary objective was to investigate the hippocampal gene expression of insulin-like growth factor two (IGF2), a member of the receptor tyrosine kinase family, which is related to insulin signaling and similarly to the effects of DS on the mechanisms of cholinergic neurotransmission [40]. In a separate study, we observed that Illumina analysis pointed to enhanced hippocampal expression of this gene and related molecules of IGF1/IGF2 signalling following DS administration in chronically stressed mice with comparison to vehicle-treated animals (Strekalova and LePrince, unpublished results; Strekalova and Malin, in preparation). Importantly, IGF2 was found to interact with IGF1 and IGF2 receptor types in the brain to induce its biological effects [41]. IGF2 can effectively bind to the insulin receptor while alternative splicing revealed a difference in affinity for central and peripheral receptors and elucidated the structural determinants for highaffinity binding [42-44].

Here, we have used a variant of a recently validated mouse model of stress-induced anhedonia [45,46]. Anhedonia, a decreased ability to experience pleasures, is a core symptom of human depression [47], which in rodents is regarded to be reflected by a decreased intake of sucrose or other palatable solutions $[48,49]$ and is reversible by antidepressants [5,50,51]. In the paradigm employed here, anhedonia, which is defined as a decrease below $65 \%$ in sucrose preference over water, occurs in a subgroup of animals. The anhedonic group, unlike the non-anhedonic group, exhibits increased floating in the forced swim test and disruptions in novelty exploration, contextual learning in the step-down inhibitory avoidance test and LTP in the CA1 area of the hippocampus. Furthermore, the anhedonic group also displays changes in EEG sleep patterns correlating to those seen in depressed humans. Chronic treatment with citalopram and imipramine counteracts the manifestation of stressed induced depressive-like traits in mice [45,52-54]. In this study, a 10-day stress protocol comprises of night time rat exposure and day time application of social defeat. Induction time of anhedonia was considerably shortened by the dual application of stressors, each of which was shown to effectively induce a hedonic deficit $[15,46]$. Intraperitoneal administration of DS at $25 \mathrm{mg} / \mathrm{kg} /$ day for 7 days was chosen since the same treatment was found to induce neurochemical alterations and beneficial behavioral effects lasting up to at least two weeks [28]. As a reference, the tricyclic imipramine ( $7 \mathrm{mg} / \mathrm{kg} /$ day) was delivered via drinking water 1 week before the onset of stress and throughout the entire stress procedure in accordance to a previously validated protocol [53]. Separate studies using the same model as the current study showed that one-week pre-treatment with daily intraperitoneal imipramine injections (15 mg/kg/day) in CD1 mice significantly attenuated stress-induced changes in the sucrose and forced swim test as compared with vehicle-injected animals [53].

\section{Methods}

\section{Animals and housing}

For the chronic stress experiment, we used male CD1 mice, widely used in behavioral, biochemical and molecular research. Male mice (age: 3 months) were purchased from Charles River (Sulzfeld, Germany). Ten days before the behavioral experiments, mice were housed single-caged under a reverse $12 \mathrm{~h}: 12 \mathrm{~h}$ lightdark cycle (lights on: 21:00 h) in standard laboratory conditions $\left(22 \pm 1^{\circ} \mathrm{C}, 55 \%\right.$ humidity, food and water ad libitum). All experiments were carried out in accordance with the European Committees Council Directives and had been approved by the Animal Experimental Committee of Claude Bernard University of Lyon and the Animal Ethical Committee of the University of Maastricht.

\section{General conditions of experiment}

Parameters of social behavior were determined one week before the chronic stress procedure in a social interaction test as described elsewhere [46,53]. Body weight and baseline preference to a $1 \%$ sucrose solution (see 
Sucrose Test) were evaluated as well. The experimental and control groups were balanced upon these parameters [46,53]. Together, 75 mice were assigned to a stress group and 25 controls constituted a non-stressed control group. Among animals from a stress group, twenty five mice received either no treatment, were treated with imipramine or with DS. Control mice were either not treated $(n=8)$, treated with imipramine $(n=8)$ or DS $(n=9)$. In control and stress groups, imipramine (7 $\mathrm{mg} / \mathrm{kg} /$ day) was administrated via drinking water starting 7 days prior the onset of stress and lasting the entire duration of the stress procedure (Figure 2).

The current reference antidepressant treatment was selected because of its maximal effects in lowering the rate of stress-induced anhedonia over other methods of delivery and doses of antidepressants [53,55]. Previous experiments revealed a weaker effect of one-week antidepressant pre-treatment with daily i.p. injections of imipramine $(15 \mathrm{mg} / \mathrm{kg} /$ day $)$ in CD1 mice for stressinduced depressive-like changes [53]. DS was administrated during 7 consecutive days preceding chronic stress. Additionally to baseline measurements, sucrose consumption tests were performed after 7 and 10 days of the chronic stress procedure (see Rat exposure while in a small container, Social defeat stress); animals were weighed weekly during the study and at the end of the stress protocol. On day 2 after stress, animals were tested in the dark/light test; on days 3 and 4, step down avoidance test was performed. Five days after the termination of the stress procedure, mice were tested in the forced swim test (see below) and on the next day sacrificed for gene expression analysis (see below; Figure 2).

\section{Chronic stress experiment}

The chronic stress procedure lasted 10 days (Figure 2). Each day, stressors were used in the same sequence: between 18.00 and 9.00 rat exposure while in a small container was applied. 30-min sessions of social defeat were employed twice daily between 11:00 and 16:00. An intersession interval between the application of two social defeat stress sessions and between social defeat and ratexposure procedures was at least $2 \mathrm{~h}$.

\section{Rat exposure while in a small container}

Mice were introduced to transparent glass cylindrical containers $(15 \mathrm{~cm} \times \varnothing 8 \mathrm{~cm})$ and placed into the rat cage (15-h exposures were performed between $18.00-9.00)$.

\section{Social defeat stress}

Social defeat procedures took place during the dark phase; to enable a visual control over the residentintruder confrontation, the test was carried out under red light. In a preliminary test, aggressive individuals of the CD1 mouse strain that were able to attack the counter-partners in less than $60 \mathrm{~s}$ without injuring them were selected for this procedure similar to commonly used protocols of social defeat stress [56,57]. These animals were introduced in the home cages of mice from the stress group during social defeat sessions, deviating from originally proposed paradigms of social defeat [58] but broadly used in a variety of experimental situations $[57,59,60]$. Social interaction was set up in the home cage of stressed animals as it enhances the impact of the stress procedure in a lasting manner. In a variant procedure, a defeated animal is left in chronic contact with the olfactory cues of the aggressive intruder, such that exposure to a psychological stressor is chronic although the actual agonistic experience is intermittent. Average duration of each session was $30 \mathrm{~min}$ in accordance with commonly used protocols [58,60]. During social defeat stress, test mice typically showed flight response, submissive posture and vocalization. Pairs of animals were carefully observed in order to exclude any physical harm. In rare cases of its incidence, aggressive individuals were immediately removed from the cage of resident mice. Total duration of social defeat stress was 10 days,

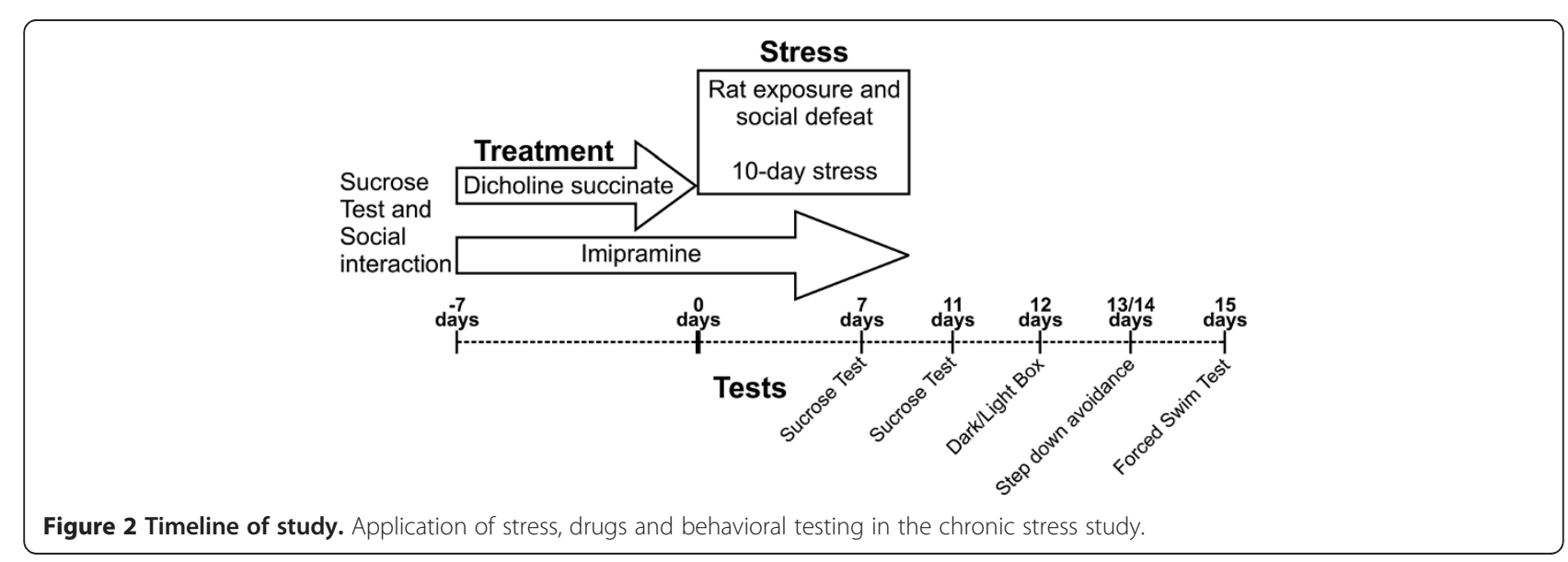


congruent with previously published studies that were using aggressive CD1 mice $[53,55]$.

\section{Sucrose test}

Mice from all groups were simultaneously given for $8 \mathrm{~h}$ (between $9.00-17.00 \mathrm{~h}$ ) a free choice between two bottles, one with $1 \%$-sucrose solution and another with tap water. To prevent possible effects of side-preference in drinking behavior, bottle position was switched after $4 \mathrm{~h}$. No previous food or water deprivation was applied before the test. To minimize the spillage of liquids during sucrose test, bottles were filled in advance and kept inverted for at least $12 \mathrm{~h}$ prior to testing in the same room where testing took place. This method was shown to ensure a low error of measurement (up to $0.1 \mathrm{ml}$ ). To decrease the variability in sucrose consumption during the very first exposure to sucrose solution (baseline sucrose test), $18 \mathrm{~h}$ before baseline animals were allowed to drink a $2.5 \%$ sucrose solution in a one-bottle paradigm for $2 \mathrm{~h}$. The intake of water and sucrose solution was estimated by weighing the bottles before and after free access to the liquids. Sucrose preference was calculated as a percentage of the consumed sucrose solution from the total amount of liquid drunk:

$$
\begin{aligned}
\text { Sucrose Preference }= & {[\mathrm{V}(\text { Sucrose solution }) /} \\
& \mathrm{V}(\text { Sucrose solution })+\mathrm{V}(\text { Water })] \\
& \times 100 \%
\end{aligned}
$$

A decrease of sucrose preference to a level below $65 \%$ measured at the $10^{\text {th }}$ day of continuous stress application was taken as a criterion for anhedonia. This criterion was based on the fact that none of the control animals exhibited $<65 \%$ preference for sucrose at that time point of the study. In addition, our previous results indicated that mice matching this criterion showed a depressive-like syndrome [53,61].

\section{Forced swim test}

Forced swim test was performed five days following termination of the stress procedure as previously described [46,53]. We used a large size pool (square pool: $21 \mathrm{~cm} \times$ $42 \mathrm{~cm} \times 15 \mathrm{~cm}$ ) illuminated with red lighting, water temperature was kept at $30^{\circ} \mathrm{C}$ and water height was $10 \mathrm{~cm}$. The modified forced swim test employed here was shown to prevent behavioral artifacts in this test caused by chronic stress-induced hyperlocomotion. Previous studies show that, with standard protocols of the forced swim test [62], chronically stressed mice exhibit hyperactivity which masks depressive-like behaviors in most behavioral tests [62]. For instance, chronically stressed C57BL6N mice show increased swimming behavior in brightly illuminated pools that is abolished with a low dosage of diazepam or testing these animals under red light [62]. Mice were introduced $2 \mathrm{~min}$ to the pool for a single swimming session. The latency of the first episode of floating determined as absence of any directed movements of the animals heads and bodies (duration more than $3 \mathrm{sec}$ ) and duration of floating were scored off-line. Visual scoring was validated as described elsewhere [63] with CleverSys software (CleverSys, VA, USA).

\section{Dark-light box}

The dark/light box consisted of two Plexiglas compartments, one black/dark $(15 \mathrm{~cm} \times 20 \mathrm{~cm} \times 25 \mathrm{~cm})$ and one lit $(30 \mathrm{~cm} \times 20 \mathrm{~cm} \times 25 \mathrm{~cm})$ connected by a tunnel. Mice were placed into the black compartment from where they could visit the lit box illuminated by a light intensity of 5 Lux. Our studies showed that with the classical protocol of the dark-light box, chronically stressed mice exhibit light-induced hyperlocomotion that confounds the evaluation of anxiety-related behaviors in this paradigm [62]. In chronically stressed C57BL6N mice, increase in time spent in the lit compartment under lighting of 600 Lux is abolished with a low dosage of diazepam; the same effect as the treatment can be achieved by dimming down the illumination or using red light [62]. Latency of the first visit to the lit box, total duration spent therein and number of visits to this anxiety-related area were scored by visual observation over $5 \mathrm{~min}$.

\section{Step-down inhibitory avoidance learning test}

Control, stressed non-anhedonic and stressed anhedonic mice were analyzed for hippocampus-dependent memory in a step-down inhibitory avoidance paradigm. The step-down apparatus (Technosmart, Rome, Italy) consisted of a transparent plastic cubicle $(25 \mathrm{~cm} \times 25 \mathrm{~cm} \times$ $50 \mathrm{~cm}$ ) with a stainless-steel grid floor (33 rods $2 \mathrm{~mm}$ in diameter) onto which a square wooden platform $(7 \mathrm{~cm} \times$ $7 \mathrm{~cm} \times 1.5 \mathrm{~cm})$ was placed. A shocker was used to deliver an alternating electric current $(A C, 50 \mathrm{~Hz}$, Evolocus, Terrytown, NY, USA). In this paradigm, animals were trained not to step down from a platform onto a grid floor to avoid an electric shock. During the training session, mice were placed onto the platform inside a transparent cylinder for $30 \mathrm{~s}$ to prevent them from immediately stepping down. After removal of the cylinder, the time until the animal left the platform with all four paws was measured as baseline latency of step down. Immediately after step down, mice received a single electric foot-shock $(0.5 \mathrm{~mA}, 2 \mathrm{sec})$ and returned to their home cages. Twenty four hours later, during the recall trial session, animals faced the same context as in the training session. Latency of step down with all four paws was measured until $180 \mathrm{~s}$ elapsed. According to previously validated criteria for the acquisition of the 
step down avoidance task [38,39], an increase of latencies measured in animals during a recall session are taken as a sign of long-term learning.

\section{Administration of compounds in chronic stress study}

Imipramine (Sigma-Aldrich, St. Louis, MO, US) was dissolved in tap water; the solution was freshly prepared every 2-3 days. Since imipramine is light sensitive, bottles were protected by aluminum covers. The calculation of the concentration of imipramine in drinking water was based on the previously evaluated mean volume of daily water consumption in CD1 mice that was about $3.5 \mathrm{ml}$ and on the dosage of treatment. Dosage for imipramine was set at $7 \mathrm{mg} / \mathrm{kg} /$ day as previous studies showed that chronic administration of imipramine at $15 \mathrm{mg} / \mathrm{kg} /$ day with drinking water, but not $7 \mathrm{mg} / \mathrm{kg} /$ day, significantly affects sucrose intake and locomotor behaviour in naive C57BL/6 N mice [55]. Imipramine was delivered with drinking water starting 1 week before the onset of stress and then throughout the entire duration of the chronic stress procedure. DS, provided by Buddha Biopharma Oy Ltd (Helsinki, Finland), was dissolved in water for injection and administrated via daily i.p. injections at $25 \mathrm{mg} / \mathrm{kg} /$ day for 7 consecutive days; this scheme of treatment was demonstrated to evoke memory-enhancing effects in mice and rats and neurochemical effects lasting over a period of two weeks [28]. The volume of DS and vehicle injections was $0.01 \mathrm{ml} / \mathrm{g}$ body weight $0.01 \mathrm{ml} / \mathrm{kg}$.

\section{Brain dissection}

Mice were sacrificed by cervical dislocation. The brains were quickly removed and dissected on ice, dissected hippocampi material were kept frozen at $-80^{\circ} \mathrm{C}$.

\section{Real-time PCR assay}

Total RNA was isolated from mouse brain using RNeasy RNA extraction kit with DNaseI treatment following the manufacturer's instructions (Qiagen, Hilden, Germany). Using random primers and Superscript III transcriptase (Invitrogen, Darmstadt, Germany), $1 \mu \mathrm{g}$ total RNA was converted into cDNA. Specific primers for IGF2 gagttca gagaggccaaacg (forward), ttagtgtgggacgtgatgga (reverse) were purchased from Sigma-Aldrich (Sigma-Aldrich, St. Louis, MO, US). The housekeeping gene glyceraldehydes-3-phosphate dehydrogenase (GAPDH) was used as a reference gene for quantification. PCR was performed with $50 \mathrm{ng}$ cDNA in a $25 \mu \mathrm{l}$ reaction volume containing a SYBR Green Master Mix (Roche, Mannheim, Germany). Amplification was carried out utilizing a Roche LightCycler 480 sequence detection system (Roche). Cycling conditions were $50^{\circ} \mathrm{C}$ for $2 \mathrm{~min}, 95^{\circ} \mathrm{C}$ for $10 \mathrm{~min}$ followed by a 40 -cycle amplification at $95^{\circ} \mathrm{C}$ for $15 \mathrm{~s}$, and $57^{\circ} \mathrm{C}$ for $1 \mathrm{~min}$. Experiments were repeated two times and samples were analyzed in triplicate. Results of the real-time PCR data were represented as $\mathrm{Ct}$ values, where $\mathrm{Ct}$ is defined as the threshold cycle of PCR at which amplified product was first detected. To compare the different RNA samples, we used the comparative $\mathrm{Ct}$ method and compared the RNA expression in samples to that of the control in each experiment.

\section{Statistical analysis}

Data were analyzed with GraphPad Prism version 5.00 for Windows (San Diego, CA, USA) using two-way ANOVA followed by Bonferroni post-tests; where appropriate, one-way ANOVA with Tukey's Multiple Comparison Test was utilized while Fisher's exact test was used to compare group size. The level of confidence was set at 95\% $(\mathrm{p}<0.05)$ and data are shown as mean \pm SEM unless otherwise stated.

\section{Results}

Assessment of anhedonia induction

Initially, mice assigned to distinct experimental groups had a similar sucrose preference (Figure 3A), intake of sucrose solution and water, as well as body weight (data not shown). Two-way ANOVA revealed a significant difference between stress and control groups $(F=11.9$, $D F n=1 ; D F d=12, p=0.0058)$ while Bonferroni's indicated that the non-treated stressed group had a significant decrease in sucrose preference $(p<0.05)$ unlike the imipramine and dicholine succinate treated groups which were not significant; indicating the ability of DS, like imipramine, to prevent a reduction in sucrose preference for the stressed cohort (Figure 3B). During the chronic stress study, sucrose preference was assessed at day 7 and 10 (end of stress, Figure 3C, D E) affirming that only the non-treated stress group showed a significant decrease in sucrose consumption $(F=12.75, D F n=1$, $D F d=87, p=0.0006)$ and at day 10 the mean for the nontreated stress group $($ mean $=64.06)$ dropped below the defined threshold for anhedonia (sucrose preference below 65\%). Neither the imipramine nor the DS treated stressed groups showed a significant change in sucrose preference at either day $(F=1.686, D F n=1, D F d=89, p=0.1975$ and $F=2.252, \quad D F n=1, \quad \mathrm{DFd}=90, \quad p=0.1369, \quad$ respectively) reiterating the ability of both DS and imipramine to prevent a decrease in sucrose preference for the stressed animals.

Previous studies have evidenced the significance of absolute sucrose intake as a parameter sensitive to the effects of antidepressants in chronic stress paradigms $[53,64]$. A counteraction of stress-induced decrease in absolute sucrose intake is taken as a sign of antidepressant-like effects of the treatment [48]. Following the stress procedure, absolute sucrose intake was measured (Figure 3F) and two-way ANOVA with Bonferroni's post-test attested that only non-treated 

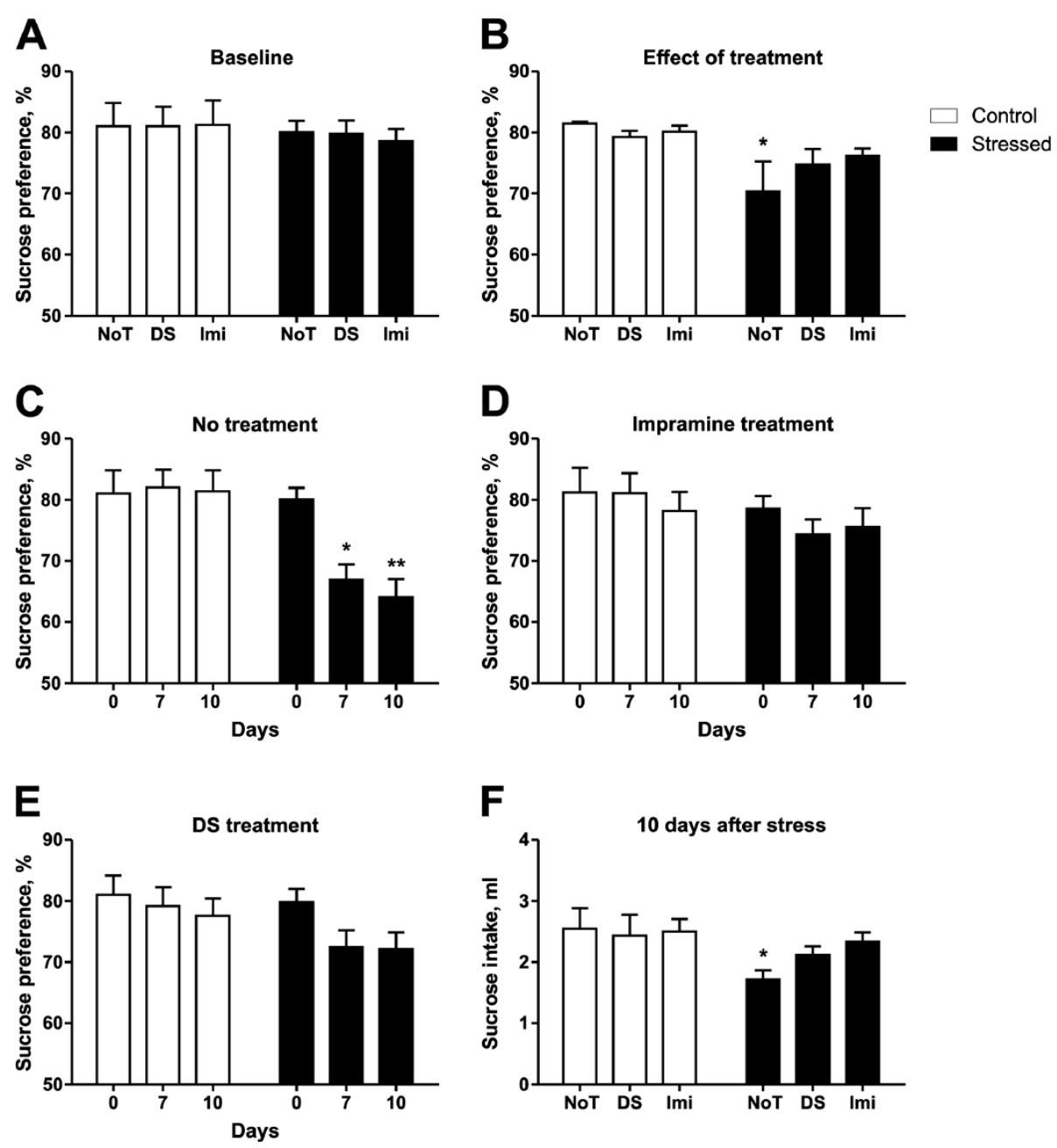

Figure 3 Imipramine and dicholine succinate counteract stress-induced decrease in sucrose preference and sucrose intake. (A) Groups of mice assigned for planned treatment had similar means of sucrose preference before the beginning of dosing. (B) Two-way ANOVA revealed a significant effect for the stress condition in sucrose preference $F=11.9, D F n=1, D F d=12, p=0.0058^{*}$ vs respected control. (C) NoT stress mice showed a significant reduction for sucrose preference at days 7 and 10 in relation to the stress condition $F=12.75, D F n=1, D F d=87, p=0.0006$, Bonferroni day $7, p<0.05^{*}$ respected control; day $10, p<0.01{ }^{* *}$ vs control. $(\mathbf{D}, \mathbf{E})$ Imi and DS stress mice did not show significant differences neither at day 7 nor day 10 for the stress condition $F=1.686, D F n=1, D F d=89, p=0.1975$ and $F=2.252, D F n=1, D F d=90, p=0.1369$ respectively. (F) Following chronic stress, the total sucrose intake was measured and two-way ANOVA revealed an overall condition effect while Bonferroni showed a significant reduction in sucrose intake only in the NoT stress group $F=5.352, D F n=1, D F d=88, p=0.0230$, Bonferroni: NoT $p<0.05$, DS, Imi $p>0.05^{*}$ vs respected control. NoT: non-treated group; Imi: imipramine-treated group, DS: DS-treated group. Data is shown as mean \pm SEM.

stress mice had a significant decrease in sucrose intake $(\mathrm{F}=5.352, \quad \mathrm{DFn}=1 ; \mathrm{DFd}=88, \mathrm{p}=0.0230$, Bonferroni: NoT $p<0.05$, DS, Imi $\mathrm{p}>0.05)$ The total number of anhedonic mice observed among the imipramine-treated $(n=6)$ and DS-treated $(n=8)$ stressed groups was lower than in the non-treated stressed group $(\mathrm{n}=14, \mathrm{p}=0.02$ and $p=0.08$, respectively, Fisher's exact test) further suggesting that both compounds counteract a development of stress-induced anhedonia.

\section{Effects of treatment on floating behavior}

Latency to floating was significantly altered by treatment in the forced swim test as revealed by two-way ANOVA
$(F=4.652, \quad D F n=2, \quad D F d=89, \quad p=0.0120) ;$ however, Bonferroni's post-test did not detect any differences between stressed and control groups suggesting that nontreated animals were significantly faster to quit swimming compared with treated animals. As with latency to floating, the duration of floating was significantly divergent between control and stress cohorts but no differences were seen between groups $(F=5.333, D F n=1$, $D F d=89, p=0.0232$, Figure 4A). The effect of treatment was robust albeit not significant $(p=0.0590)$ indicating that the stressed condition had a significant effect on floating duration while non-treated animals had a very strong tendency for increased periods of floating suggesting 

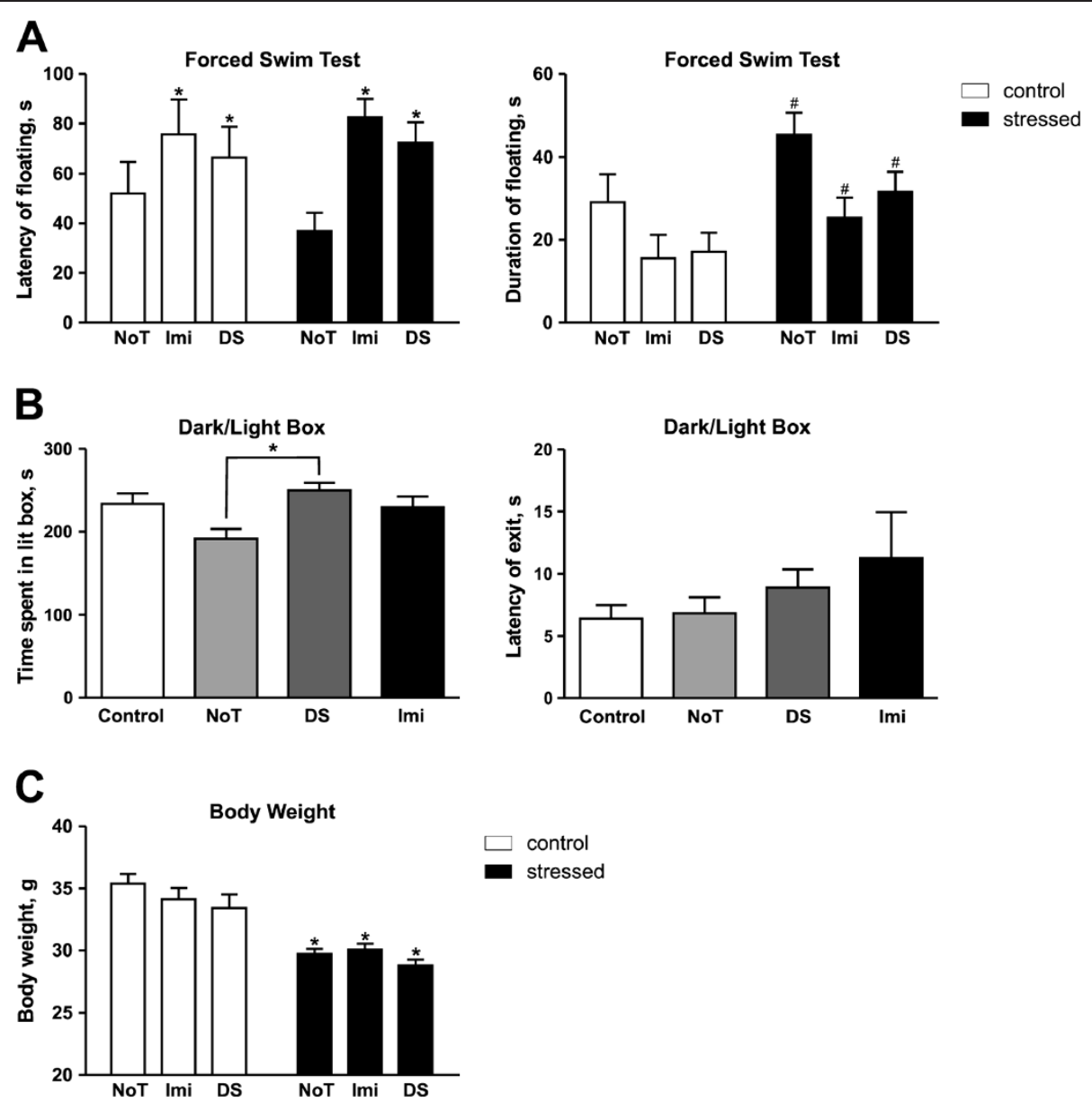

Figure 4 Dicholine succinate reduces stress-induced floating and anxiety-like behaviors, but not a decrease of body weight. (A) Latency of floating had an overall significant difference for treatment while the duration of floating had an overall significant difference for the stress condition $F=4.652, D F n=2, D F d=89, p=0.0120$ and $F=5.333, D F n=1, D F d=89, p=0.0232$ respectively two-way ANOVA; ${ }^{*}$ vs non-treated, \# vs respected controls. (B) ANOVA revealed a significant difference for time spent in the lit compartment with Tukey showing only a difference between the Not and DS treated stress groups $F=4.469, D F n=3, D F d=39, p=0.0086$, Tukey $p<0.01 ; *$ vs respected control. No significant difference in latency of exit was observed. (C) Two-way ANOVA revealed a significant difference in body weight for the stress condition in all groups $F=66.81, D F n=1, D F d=89, p<0.0001 .{ }^{*}$ vs respected controls NoT: non-treated group; Imi: imipramine-treated group, DS: DS-treated group. All data is shown as mean \pm SEM.

that DS and imipramine treatment both had a positive antidepressant-like effect.

\section{Evaluation of anxiety scores}

The level of anxiety was significantly altered between groups as revealed by total duration spent in the lit compartment (one-way ANOVA, $F=4.469, D F n=3, D F d=39$, $p=0.0086$, Figure 4B) Tukey's post-test showed that the non-treated stress group spent a very significantly diminished duration $(p<0.01)$ in the lit compartment compared with the DS treated stress group; no significant differences were revealed amidst the other groups indicating the ability of DS to block stress-induced anxiety. Latency to exit was not different between any of the groups (one-way ANOVA, $F=1.232, D F n=3, D F d=41, p=0.3103$ ).

\section{Changes in body weight}

After the termination of stress, body weight was significantly shifted between control and stress animals and all stress groups showed an extremely significant decrease in body weight compared with controls (two-way ANOVA, $F=66.81, \quad D F n=1, \quad D F d=89, \mathrm{p}<0.0001$, Bonferroni, NoT, Imi, DS $p<0.001$, Figure 4C).

\section{Step-down avoidance learning}

All stress groups tested showed a significant difference on test day as compared to the baseline day (one-way ANOVA, $F=23.27, D F n=7, \quad D F d=192, \quad p<0.0001$, Figure $5 \mathrm{~A}$ ) suggesting that all groups were able to acquire the task while no observed difference in baseline shows that initial anxiety levels were the same between groups. Tukey's post-test revealed that non-treated stress 


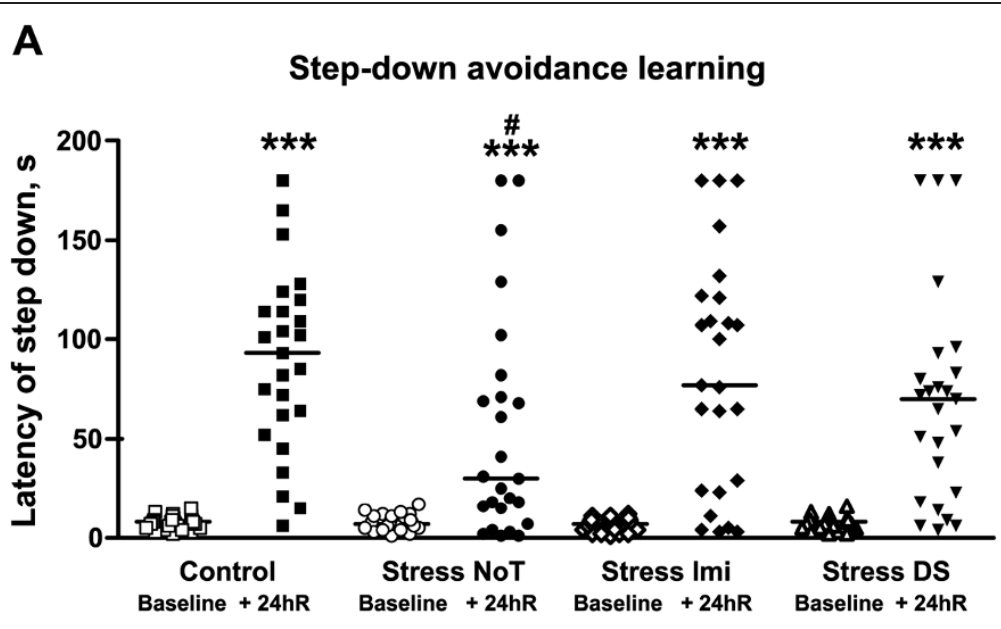

B

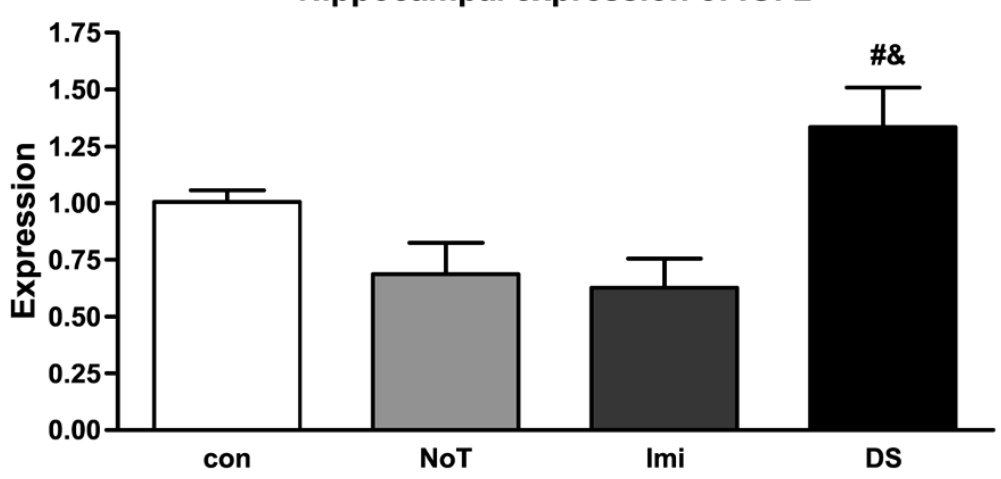

Figure 5 Effect of imipramine and dicholine succinate on step-down avoidance learning and hippocampal expression of IGF2. (A) All groups showed a significant increase in the latency to step down as compared to their respective baselines one-way ANOVA $F=23.27, D F n=7$, $D F d=192, p<0.0001^{* * *}$ vs baseline while the NoT group was significantly lower for the recall test compared to control indicating a disruption in contextual learning \# vs control. (B) There was an overall significant difference seen in the hippocampal gene expression for IGF2, while Tukey's post-test revealed differences for IGF2 gene expression between DS and Imi treated groups and DS and NoT treated groups $p<0.01, F=6.232$, $D F n=3, D F d=33, p=0.0018$. \# vs NoT \& vs Imi; NoT: non-treated group; Imi: imipramine-treated group, DS: DS-treated group. All data is shown as mean \pm SEM.

animals were significantly different compared to controls in the $24 \mathrm{hr}$ recall showing reduced latencies to step down $(p<0.05)$ whilst imipramine and DS treated stress animals did not show any difference, thus suggesting stress disrupted learning in non-treated animals and demonstrating the ability of DS and imipramine to preserve contextual memory for stressed animals.

\section{Hippocampal gene expression of insulin-like growth factor 2}

IGF2 expression levels were measured following the stress procedure. Hippocampal expression levels of IGF2 were significantly altered in stressed animals (oneway ANOVA, $F=6.232, D F n=3, D F d=33, p=0.0018$ Figure 5B). Post-test with Tukey revealed that DS treated animals had a significant increase in IGF2 expression levels compared with non-treated and imipramine treated groups $(p<0.01)$ while no significant differences were observed between other groups.

Altogether, pre-stress treatment with imipramine and DS prevented a stress-induced decrease of sucrose intake and preference, counteracted a stress-induced increase in floating, conserved contextual inhibitory learning and averted anxiety-like behavior; however, the applied drugs did not prevent a loss in body weight. A pronounced up-regulation of IGF2 gene expression in the hippocampus accompanied these behavioral effects of DS treatment in chronically stressed mice.

\section{Discussion}

Initial values of sucrose test parameters were similar between all groups (Figure 3A) and stress exposure lowered sucrose preference in agreement with other reports $[49,61,65]$. Stressed mice treated with DS showed no significant change in sucrose preference measured on the 
$7^{\text {th }}$ and $10^{\text {th }}$ day of stress as compared to control animals (Figure 3E). Administration of the classical antidepressant imipramine resulted in a similar effect. Earlier, we have shown in a model of stress-induced anhedonia that the stress-induced decrease in sucrose preference is paralleled by a reduction in sucrose intake $[46,53]$. In particular, a disruption of synaptic plasticity and pronounced behavioral despair in the forced swim test were observed in mice, which showed a decrease in both sucrose intake and preference but not a reduced sucrose preference alone, which occurs exclusively at the expense of high water intake $[45,51,53]$. Thus, the partial preclusion of the stress-induced reduction for both sucrose preference and consumption by treatment with imipramine and DS manifests their antidepressant-like activity in our study. Importantly, administration of imipramine and DS did not alter sucrose test parameters in control animals ruling out any possible confounding artifacts for sucrose test measurements which could be related to treatment. Imipramine, used as a reference drug in this experiment, is well documented to counteract the stress-induced decrease in sucrose intake and preference seen in rodents $[51,65]$. Overall, our data suggest that chronic administration of imipramine and DS has the potential to counteract the development of stress-induced anhedonia, i.e. elicits an antidepressantlike activity in the mouse paradigm employed in the present study.

Described above evidences, for antidepressant-like effects of DS in the sucrose test, are in line with the outcome from the forced swim test. While the effects of chronic stress on the latency to the first episode of floating were not significant, DS and imipramine treated mice had significantly higher values of this parameter (Figure 4A). DS administration strongly reduced the duration of floating in the chronic stress experiment suggesting that treatment with DS prevents a stress-induced state of behavioral despair as measured by elevated floating behavior (Figure 4A) $[45,46,48,66]$. In the current work, these antidepressant like effects observed with DS administration were also demonstrated for treatment with imipramine; earlier, we reported congruent changes in the forced swim test following chronic administration of citalopram [53]. Coinciding with these results, another insulin sensitizer, rosiglitazone, was reported to reduce immobilization and floating behaviors in mouse tail suspension and forced swim tests respectively [35].

Both treatment with imipramine and DS decreased anxiety scores as shown by increased time spent in the lit compartment in the dark/light box indicating their anxiolytic and anti-stress effects (Figure 4B). Such effects are well documented for imipramine and other tricyclics [48]. Elevated anxiety was found to parallel anhedonia induction in chronic stress models $[15,45,48,49]$.
In the present study, the stress-induced loss in body weight does not correlate with an occurrence of anhedonia and depressive-like syndrome in mice. However, it has been shown that antidepressant effects of pharmacological treatment parallel a restoration of body weight $[48,67]$. We did not find such an effect with imipramine and DS treatment (Figure 4C) in the present study but it must be noted that a lack of positive effects on the restoration of body mass in depressed patients is well documented for many antidepressants including fluoxetine and other SSRIs $[48,66]$.

Treatment with imipramine and DS prevented stressinduced memory impairment in the step-down inhibitory avoidance task (Figure 5A). The latency of step down measured twenty four hours after training session was previously validated as a reliable measure of hippocampus-dependent performance in mice $[38,39]$. Deficits in hippocampus-dependent performance were earlier shown to be a specific feature of stressed anhedonic mice as compared to stressed individuals without a depressive syndrome in various chronic stress paradigms. Treatment with citalopram was shown to rescue contextual fear conditioning in a model of stressinduced anhedonia $[38,45,53]$. Since imipramine administration also precluded deficits in the step-down avoidance test, beneficial effects of DS on learning can be accounted for by its antidepressant action which is generally accompanied by an improvement in cognitive function in clinical and pre-clinical studies. These data are in line with ameliorative effects of DS on hippocampus- and cortex-dependent learning in stepthough and Morris water maze paradigms which this drug exerted under pathological conditions of diverse origins $[28,29]$.

Our study evidenced a sharp increase in hippocampal gene expression of IGF2, a member of the insulin gene family with known neurotrophic properties, after administration of DS, but not imipramine, in stressed mice (Figure 5B). Utilizing the hippocampi of mice from the same experimental groups (five animals per each group were analyzed), gene expression profiling was performed using Illumina technology (Integragen, Evry, France and Northwestern Chicago University, USA). This study revealed significant effects of DS on the expression of a number of functionally important genes (Strekalova and Malin, in preparation). Therefore, total RNA was isolated using RNeasy Mini Kit (Qiagen, Hilden, Germany). Total RNA samples were hybridized to IlluminaBeadChips (MouseRef-8 v2 Expression BeadChip; Illumina, Inc. San Diego, CA, USA) which were prepared using the IlluminaTotalPrep RNA Amplification kit (Applied Biosystems/Ambion, Carlsbad, CA, USA); the samples were assigned to the chips in random order with the constraint that no two samples from the same group 
were assigned to the same chip, to avoid confounding of experimental groups with the chips. Microarray data were analyzed using standard analysis procedures which included assessment of the overall quality of array data and statistical evaluation of differentially expressed genes (Integragen, Evry, France). Once the quality of array data was confirmed, the Gene Chip Operating System (Illumina, Inc. San Diego, CA, USA) was used to calculate signal intensities, detection calls, and their associated $\mathrm{P}$ values for each transcript on the array. Gene expression was normalized to the expression of the house gene beta-actin, due to its stable expression, and calculated as percent mean of the control group. Differences in gene expression between groups were evaluated using ANOVA followed by Fisher's Least Significant Difference test.

In line with the outcome from mRNA evaluation (Figure 5B), these data revealed a significant increase of IGF2 expression in stressed DS-treated mice (163.1 $\pm 30.17 \%$ from control) and its significant decrease in stressed mice that were not treated $(83.0 \pm 4.49 \%$ from control). This study indicated that stressed DS-treated mice showed a significant expression enhancement of Htra1, HtrA serine peptidase 1 which cleaves IGF-binding proteins (IGFBPs) from IGF1 and IGF2 and activates these factors, in comparison to non-treated mice (144.3 \pm 9.16 vs. $119.2 \pm 17.6 \%$ from control, respectively). Preliminary data showed no such changes of IGF2 in the nonstressed control group. Also, this experiment revealed significant effects of DS on the expression of other elements of the IGF1/IGF2 system in chronically stressed mice, including Htra1, as well as IGF1 and IGF1 receptor, the insulin receptor and several insulin-like growth factor binding proteins. Again, no such changes were detected in non-stressed mice treated with DS. While it is important to study above-mentioned findings with additional methods, they generally support our data on elevated mRNA of IGF2 in the hippocampus of DStreated stressed mice and suggest this elevation to be a part of systemic changes in IGF1/IGF2 signaling in these animals. A lack of such molecular effects in naive mice treated with DS might be due to distinct functional states of the IGF1/IGF2 system during stress and resting conditions; whereas, the activation of this signaling might occur as an adaptive mechanism in response to biological challenges.

A comparison of pharmacologically naïve anhedonic versus resilient animals in changes of the abovementioned elements of IGF1/IGF2 signaling speaks in favor of the latter view. Our studies revealed an intriguing difference in the IGF2 expression between nontreated stressed anhedonic and resilient animals $(58.8 \pm 2.32 \%$ vs. $107.2 \pm 8.7 \%$ from control, respectively), suggesting the elevated IGF2 to be a correlate of stress resilience while its decrease as a parallel of susceptibility to a depressive-like state. Moreover, the expression of Htra1 was reduced in non-treated anhedonic and essentially increased in the resilient group $(91.08 \pm 6.16 \%$ vs. $148.34 \pm 11.16 \%$ from control, respectively). Anhedonic and non-anhedonic groups had differential expressions in most of the other above-listed elements of the IGF1/ IGF2 signaling system (Strekalova and Malin, in preparation). Thus, the outcome from the gene expression profiling experiment is in line with a suggestion that enhanced expression of IGF2 can mediate resilience to stress-induced anhedonia induced by administration of DS in our study.

IGF2 is widely expressed throughout the brain and is abundant in the hippocampus [68]. Various challenges such as acute hypoxia, exposure to toxicity stress and cerebral ischemia were shown to induce long-lasting changes in IGF2 expression which is considered to have an important neuroprotective function [69-71]. IGF2 was recently shown to be an important regulator of hipppocampal neurogenesis in the context of extinction in fear conditioning learning [72]. Moreover, IGF2 was shown to enhance adult neurogenesis [73]. Our results evidenced suppressive effects of stress on hippocampal levels of IGF2 demonstrating that chronic stress in mice has a tendency to decrease the content of this neurotrophic factor that might be associated with its abovementioned role in the regulation of neurogenesis which is inhibited by stress [74]. In order to immediately address how crucial the role of IGF2 in the development of stress-induced depressive syndrome might be, a chronic intrahippocampal administration of this molecule could be applied with our model. Treatment with DS significantly elevated levels of IGF2 in stressed mice above that of controls. The mechanisms of this effect can be due to an earlier demonstrated DS-induced enhancement of choline content and acetylcholine function in the brain [28] since a functional link between this neurotransmitter system and IGF2 is particularly evidenced by increased expression of this neurotrophic factor after choline administration in the hippocampus and frontal cortex $[40,75,76]$. In these studies, choline supplementation increased levels of IGF2 in the hippocampus and changed expression of its receptors in the septum, it also enhanced IGF2-induced acetylcholine release and cholinergic neurontransmission [40]. Importantly, there was an increase of choline acetyltransferase activity after DS treatment in rats subjected to a toxic treatment with beta-amyloid peptide-(25-35) [28] and elevated IGF2 content in our study on mice were observed two weeks after the termination of a chronic DS administration (Figure 2).

Interestingly, recent results evidenced a critical role of IGF2 in inhibitory avoidance learning as shown in the 
fear conditioning paradigm [72,77] which can additionally explain the beneficial effects of DS on performance in chronically stressed mice in the step-down inhibitory avoidance task (Figure 5A). Taking these data into account and given the fact that hippocampal IGF2 signaling regulates adult neurogenesis in the context of fear extinction learning [73] it would be of high interest to assess the expression of IGF2 in the step-down avoidance inhibitory task that is similar to the fear conditioning paradigm form of contextual learning. However, the fact that imipramine did not evoke any effect on IGF2 gene expression while exhibiting both prominent antidepressant and memory-enhancing effects similar to DS suggest that elevated expression of this molecule cannot be the sole mechanism of antidepressant and memoryenhancing effects observed for DS in the current study.

\section{Conclusions}

Together, our data suggest that the chronic administration of DS in mice before the onset of stress exerts antidepressant-, anxiolytic-like and memory-preserving effects in a mouse chronic stress depression model similar to the classical antidepressant imipramine. The effects of DS parallel a lasting increase of hippocampal expression of IGF2 that is not observed in imipraminetreated mice suggesting distinct mechanisms of beneficial action of the two drugs used here in this model of experimental depression. The latest clinical study showed the efficacy of insulin receptor sensitizers in patients who were refractory to a standard antidepressant treatment; thus, arguing for a relevance of heterogeneity in neurochemical factors underlying this disorder and its cure [36,37].

To date, one can only speculate about the specific mechanisms of the reported effects of DS here. One can hypothesize that they are mediated by neurotrophins like IGF2 that activate neurogenesis and evoke antiinflammatory effects $[74,78,79]$ as well as associated with IGF2-induced changes in expression of GluR1 [77], GABA release and receptor expression $[75,80]$ and activity of PKC- and calmodulin kinase I-dependent pathways $[75,81]$. Additionally, preliminary data suggest antiinflammatory effects of DS and other insulin receptor sensitizers which were used in clinical $[32,34,37]$ and pre-clinical studies [82]; this can per se, underlie an antidepressant effect taking into account emerging evidence for the role of inflammatory mechanisms in depression $[83,84]$.

Meanwhile, alterations in insulin signaling pathways by DS may also represent an important part of the underlying antidepressant action. A recently found antidepressant effect of the neuronal sensitizer thiazolidinedione was correlated with a reduction of insulin resistance [36] and data with pioglitazone also suggest such a relationship [37]. Although a link between DS treatment and insulin sensitivity remains to be determined in the paradigm applied here, the present study argues for the potential of agents which like DS, increase insulin signaling and thereby generating a sustainable antidepressant-like effect at least as powerful as that of tricyclics.

\section{Competing interests \\ The authors declare that they have no competing interests.}

\section{Authors' contributions}

BC participated in the chronic stress experiment, statistical analysis and drafted the manuscript; HS participated in the design of the study and coordination; DM carried out RT-PCR; AR participated in the chronic stress experiment and tissue collection; GP participated in the design of the study and coordination; RC participated in the coordination of the study and helped to draft the manuscript; TS conceived of the study, and participated in its design and coordination and helped to draft the manuscript. All authors read and approved the final manuscript.

\section{Acknowledgements}

We would like to acknowledge the important technical contribution of Mrs Aïcha Compard, Mr Vincent van Miegem and Mr Giovanni Larde, as well as irreplaceable input of Dr Emmanuel Martin from Integragen with his excellent expertise in the Illumina assay. We thank NARSAD Brain and Behavior Research Foundation, USA (17611 to T.S.) and RFBR 11-04-01411 for a support of this study.

\section{Author details}

'Interdisciplinary Center for Neurosciences, Heidelberg University, and Institute for Neuroanatomy, University Clinic Heidelberg, Im Neuenheimer Feld 307, 69120, Heidelberg, Germany. ${ }^{2}$ School for Mental Health and Neuroscience, Department of Neuroscience, Maastricht University, Universiteitssingel 40, NL 6229 ER, Maastricht, Netherlands. ${ }^{3}$ University of Wisconsin, Carbon Cancer Center, WIMR 3016, 1111 Highland Ave, Madison, WI 53705, USA. ${ }^{4}$ Institute of General Pathology and Pathophysiology, Russian Academy of Medical Sciences, Baltiyskaya str. 8, 125315, Moscow, Russia. ${ }^{5}$ Institute of Gene Biology of Russian Academy of Sciences, 34/5 Vavilov str, Moscow 119334, Russia. ${ }^{6}$ Claude Bernard University, Lyon1, Faculty of Medicine, EA 4170, Av. Rockefeller 8, 69373, Lyon CEDEX 08, France.

Received: 26 March 2012 Accepted: 14 September 2012

Published: 18 September 2012

\section{References}

1. Willis T: Diabetes: A Medical Odyssey. New York: Tuckahoe; 1971.

2. Egede $L E, E$, Elis $C$ : Diabetes and depression: global perspectives. Diabetes Res Clin Pract 2010, 87:302-312

3. Ali $S$, Stone $M A$, Peters $J L$, Davies $M J$, Khunti $K$ : The prevalence of co-morbid depression in adults with Type 2 diabetes: a systematic review and meta-analysis. Diabet Med 2006, 23:1165-1173.

4. Asghar S, Hussain A, Ali SM, Khan AK, Magnusson A: Prevalence of depression and diabetes: a population-based study from rural Bangladesh. Diabet Med 2007, 24:872-877.

5. Shomaker LB, Tanofsky-Kraff M, Young-Hyman D, Han JC, Yanoff LB, Brady SM, Yanovski SZ, Yanovski JA: Psychological symptoms and insulin sensitivity in adolescents. Pediatr Diabetes 2010, 11:417-423.

6. Timonen M, Laakso M, Jokelainen J, Rajala U, Meyer-Rochow VB, KeinanenKiukaanniemi S: Insulin resistance and depression: cross sectional study BMJ 2005, 330:17-18.

7. Palinkas LA, Barrett-Connor E, Wingard DL: Type 2 diabetes and depressive symptoms in older adults: a population-based study. Diabet Med 1991 8:532-539.

8. Talbot F, Nouwen A: A review of the relationship between depression and diabetes in adults: is there a link? Diabetes Care 2000, 23:1556-1562.

9. Loktionov A: Common gene polymorphisms and nutrition: emerging links with pathogenesis of multifactorial chronic diseases (review). J Nutr Biochem 2003, 14:426-451. 
10. Hallschmid M, Schultes B: Central nervous insulin resistance: a promising target in the treatment of metabolic and cognitive disorders? Diabetologia 2009, 52:2264-2269.

11. Huang CC, Lee CC, Hsu KS: The role of insulin receptor signaling in synaptic plasticity and cognitive function. Chang Gung Med J 2010, 33:115-125.

12. Chiu SL, Chen CM, Cline HT: Insulin receptor signaling regulates synapse number, dendritic plasticity, and circuit function in vivo. Neuron 2008, 58:708-719.

13. Lin $\mathrm{CH}$, Tomioka M, Pereira S, Sellings $L$, lino $Y$, van der Kooy D: Insulin signaling plays a dual role in Caenorhabditis elegans memory acquisition and memory retrieval. J Neurosci 2010, 30:8001-8011.

14. Kikusui T, Ichikawa S, Mori Y: Maternal deprivation by early weaning increases corticosterone and decreases hippocampal BDNF and neurogenesis in mice. Psychoneuroendocrinology 2009, 34:762-772.

15. Krishnan V, Han MH, Graham DL, Berton O, Renthal W, Russo SJ, Laplant Q, Graham A, Lutter M, Lagace DC, et al: Molecular adaptations underlying susceptibility and resistance to social defeat in brain reward regions. Cell 2007, 131:391-404.

16. Spencer JL, Waters EM, Milner TA, Lee FS, McEwen BS: BDNF variant Val66Met interacts with estrous cycle in the control of hippocampal function. Proc Natl Acad Sci USA 2010, 107:4395-4400.

17. Freude $S$, Leeser $U$, Muller M, Hettich MM, Udelhoven M, Schilbach K, Tobe K, Kadowaki T, Kohler C, Schroder H, et al: IRS-2 branch of IGF-1 receptor signaling is essential for appropriate timing of myelination. $J$ Neurochem 2008, 107:907-917.

18. Govind S, Kozma R, Monfries C, Lim L, Ahmed S: Cdc42Hs facilitates cytoskeletal reorganization and neurite outgrowth by localizing the 58-kD insulin receptor substrate to filamentous actin. J Cell Biol 2001, 152:579-594.

19. Zhao WQ, Alkon DL: Role of insulin and insulin receptor in learning and memory. Mol Cell Endocrinol 2001, 177:125-134.

20. Mufson EJ, Kroin JS, Sendera TJ, Sobreviela T: Distribution and retrograde transport of trophic factors in the central nervous system: functional implications for the treatment of neurodegenerative diseases. Prog Neurobiol 1999, 57:451-484.

21. Sun X, Yao H, Douglas RM, Gu XQ, Wang J, Haddad GG: Insulin/PI3K signaling protects dentate neurons from oxygen-glucose deprivation in organotypic slice cultures. J Neurochem 2010, 112:377-388.

22. Kuhad A, Bishnoi M, Tiwari V, Chopra K: Suppression of NF-kappabeta signaling pathway by tocotrienol can prevent diabetes associated cognitive deficits. Pharmacol Biochem Behav 2009, 92:251-259.

23. van der Heide LP, Ramakers GM, Smidt MP: Insulin signaling in the central nervous system: learning to survive. Prog Neurobiol 2006, 79:205-221.

24. Williams JM, Owens WA, Turner GH, Saunders C, Dipace C, Blakely RD, France CP, Gore JC, Daws LC, Avison MJ, Galli A: Hypoinsulinemia regulates amphetamine-induced reverse transport of dopamine. PLOS Biol 2007, 5:e274

25. Daws LW, Owens A, Campos P, Gould G, Galli A, France C: Regulation of biogenic amine transporters by insulin. Hollywood, FL: Implications for antidepressant drug efficacy. In Presented at the 48th Annual Meeting of the American College of Neuropsychopharmacology; 2009.

26. Tornqvist HE, Pierce MW, Frackelton AR, Nemenoff RA, Avruch J: Identification of insulin receptor tyrosine residues autophosphorylated in vitro. J Biol Chem 1987, 262:10212-10219.

27. Rosen OM, Herrera R, Olowe Y, Petruzzelli LM, Cobb MH: Phosphorylation activates the insulin receptor tyrosine protein kinase. Proc Natl Acad Sci USA 1983, 80:3237-3240.

28. Storozheva ZI, Proshin AT, Sherstnev W, Storozhevykh TP, Senilova YE, Persiyantseva NA, Pinelis VG, Semenova NA, Zakharova El, Pomytkin IA Dicholine salt of succinic acid, a neuronal insulin sensitizer, ameliorates cognitive deficits in rodent models of normal aging, chronic cerebral hypoperfusion, and beta-amyloid peptide-(25-35)-induced amnesia. BMC Pharmacol 2008, 8:1

29. Storozhevykh TP, Senilova YE, Persiyantseva NA, Pinelis VG, Pomytkin IA: Mitochondrial respiratory chain is involved in insulin-stimulated hydrogen peroxide production and plays an integral role in insulin receptor autophosphorylation in neurons. BMC Neurosci 2007, 8:84

30. Strum JC, Shehee R, Virley D, Richardson J, Mattie M, Selley P, Ghosh S, Nock $C$, Saunders A, Roses A: Rosiglitazone induces mitochondrial biogenesis in mouse brain. J Alzheimers Dis 2007, 11:45-51.
31. Zhao $Y$, Patzer A, Herdegen T, Gohlke P, Culman J: Activation of cerebral peroxisome proliferator-activated receptors gamma promotes neuroprotection by attenuation of neuronal cyclooxygenase-2 overexpression after focal cerebral ischemia in rats. FASEB J 2006, 20:1162-1175.

32. Saubermann LJ, Nakajima A, Wada K, Zhao S, Terauchi $Y$, Kadowaki T, Aburatani H, Matsuhashi N, Nagai R, Blumberg RS: Peroxisome proliferatoractivated receptor gamma agonist ligands stimulate a Th2 cytokine response and prevent acute colitis. Inflamm Bowel Dis 2002, 8:330-339.

33. Igarashi M, Hirata A, Yamaguchi $H$, Jimbu Y, Tominaga M: Pioglitazone reduces atherogenic outcomes in type 2 diabetic patients. J Atheroscler Thromb 2008, 15:34-40.

34. Mittal R, Malhotra S, Pandhi P, Kaur I, Dogra S: Efficacy and safety of combination Acitretin and Pioglitazone therapy in patients with moderate to severe chronic plaque-type psoriasis: a randomized, double-blind, placebo-controlled clinical trial. Arch Dermatol 2009, 145:387-393.

35. Eissa Ahmed AA, Al-Rasheed NM: Antidepressant-like effects of rosiglitazone, a PPARgamma agonist, in the rat forced swim and mouse tail suspension tests. Behav Pharmacol 2009, 20:635-642.

36. Rasgon NL, Kenna HA, Williams KE, Powers B, Wroolie T, Schatzberg AF: Rosiglitazone add-on in treatment of depressed patients with insulin resistance: a pilot study. Sci World J 2010, 10:321-328.

37. Kemp DE, Ismail-Beigi F, Ganocy SJ, Conroy C, Gao K, Obral S, Fein E, Findling RL, Calabrese JR: Use of insulin sensitizers for the treatment of major depressive disorder: a pilot study of pioglitazone for major depression accompanied by abdominal obesity. J Affect Disord 2012, 136:1164-1172.

38. Strekalova T, Steinbusch HW: Measuring behavior in mice with chronic stress depression paradigm. Prog Neuropsychopharmacol Biol Psychiatry 2010, 34:348-361.

39. Strekalova T, Wotjak CT, Schachner M: Intrahippocampal administration of an antibody against the HNK-1 carbohydrate impairs memory consolidation in an inhibitory learning task in mice. Mol Cell Neurosci 2001, 17:1102-1113.

40. Napoli I, Blusztajn JK, Mellott TJ: Prenatal choline supplementation in rats increases the expression of IGF2 and its receptor IGF2R and enhances IGF2-induced acetylcholine release in hippocampus and frontal cortex. Brain Res 2008, 1237:124-135.

41. Gammeltoft S, Fehlmann M, Van Obberghen E: Insulin receptors in the mammalian central nervous system: binding characteristics and subunit structure. Biochimie 1985, 67:1147-1153.

42. Mosthaf L, Grako K, Dull TJ, Coussens L, Ullrich A, McClain DA: Functionally distinct insulin receptors generated by tissue-specific alternative splicing. EMBO J 1990, 9:2409-2413.

43. Yamaguchi Y, Flier JS, Yokota A, Benecke H, Backer JM, Moller DE: Functional properties of two naturally occurring isoforms of the human insulin receptor in Chinese hamster ovary cells. Endocrinology 1991, 129:2058-2066

44. Denley A, Bonython ER, Booker GW, Cosgrove LJ, Forbes BE, Ward CW, Wallace JC: Structural determinants for high-affinity binding of insulinlike growth factor II to insulin receptor (IR)-A, the exon 11 minus isoform of the IR. Mol Endocrinol 2004, 18:2502-2512.

45. Strekalova T, Couch Y, Kholod N, Boyks M, Malin D, Leprince P, Steinbusch HM: Update in the methodology of the chronic stress paradigm: internal control matters. Behav Brain Funct 2011, 7:9.

46. Strekalova T, Spanagel R, Bartsch D, Henn FA, Gass P: Stress-induced anhedonia in mice is associated with deficits in forced swimming and exploration. Neuropsychopharmacology 2004, 29:2007-2017.

47. Hamilton M: Development of a rating scale for primary depressive illness. Br J Soc Clin Psychol 1967, 6:278-296.

48. Willner P: Chronic mild stress (CMS) revisited: consistency and behavioural-neurobiological concordance in the effects of CMS Neuropsychobiology 2005, 52:90-110.

49. Willner P, Towell A, Sampson D, Sophokleous S, Muscat R: Reduction of sucrose preference by chronic unpredictable mild stress, and its restoration by a tricyclic antidepressant. Psychopharmacology (Berl) 1987, 93:358-364.

50. Monleon S, D'Aquila P, Parra A, Simon VM, Brain PF, Willner P: Attenuation of sucrose consumption in mice by chronic mild stress and its restoration by imipramine. Psychopharmacology (Berl) 1995, 117:453-457. 
51. Harkin A, Houlihan DD, Kelly JP: Reduction in preference for saccharin by repeated unpredictable stress in mice and its prevention by imipramine. J Psychopharmacol 2002, 16:115-123.

52. Strekalova T, Cespuglio R, Kovalzon V: Sleep structure during chronic stress and anhedonia in the mouse model of depression. In Behavioral models in stress research. Volume Ilth edition. Edited by Kalueff AV, LaPorte JL. New York: Nova Science Publishers Inc; 2009:113-129.

53. Strekalova T, Gorenkova N, Schunk E, Dolgov O, Bartsch D: Selective effects of citalopram in a mouse model of stress-induced anhedonia with a control for chronic stress. Behav Pharmacol 2006, 17:271-287.

54. Strekalova T, Steinbusch H: Factors of reproducibility of stress-induced anhedonia in chronic stress depression models in mice. In Mood and Anxiety related phenotypes in mice: characterization using behavioral tests. Edited by Gould TD. Totoway, NJ: Humana Press; 2009:153-176.

55. Nunes J, Correia M, Valenca A, Gorenkova N, Bolkunov A, Redkozubova O, Bachurin S, Steinbusch H, Strekalova T: Behavioral Effects of Chronic Administration of Imipramine With Food and Water in Tests for Depression and Anxiety in Naïve C57BL/6N Mice. EURON School "Drugs and the Brain, an update in Psychopharmacology 2010:25.

56. Kinn Rod AM, Milde AM, Gronli J, Jellestad FK, Sundberg H, Murison R: Long-term effects of footshock and social defeat on anxiety-like behaviours in rats: relationships to pre-stressor plasma corticosterone concentration. Stress 2012, 3:11-13.

57. Buwalda B, Scholte J, de Boer SF, Coppens CM, Koolhaas JM: The acute glucocorticoid stress response does not differentiate between rewarding and aversive social stimuli in rats. Horm Behav 2012, 61:218-226.

58. Miczek KA: A new test for aggression in rats without aversive stimulation: differential effects of d-amphetamine and cocaine. Psychopharmacology (Berl) 1979, 60:253-259.

59. Blanchard RJ, McKittrick CR, Blanchard DC: Animal models of social stress: effects on behavior and brain neurochemical systems. Physiol Behav 2001, 73:261-271.

60. Sgoifo A, Costoli T, Meerlo P, Buwalda B, Pico'-Alfonso MA, De Boer S, Musso $E$, Koolhaas J: Individual differences in cardiovascular response to social challenge. Neurosci Biobehav Rev 2005, 29:59-66.

61. Katz RJ: Animal model of depression: pharmacological sensitivity of a hedonic deficit. Pharmacol Biochem Behav 1982, 16:965-968.

62. Strekalova T, Spanagel R, Dolgov O, Bartsch D: Stress-induced hyperlocomotion as a confounding factor in anxiety and depression models in mice. Behav Pharmacol 2005, 16:171-180.

63. Malatynska E, Steinbusch HW, Redkozubova O, Bolkunov A, Kubatiev A Yeritsyan NB, Vignisse J, Bachurin S, Strekalova T: Anhedonic-like traits and lack of affective deficits in 18-month-old C57BL/6 mice: implications for modeling elderly depression. Exp Gerontol 2012, 47:552-564.

64. Tokarski K, Draguhn A, Gorenkova N, Schunk E, Kunchulia D, Dolgov O, Steinbusch HM, Strekalova T: Hippocampal plasticity in mice with and without hedonic deficit after stress and pre-treatment by citalopram. Hippocampus (under revision)

65. Harro J, Tonissaar M, Eller M, Kask A, Oreland L: Chronic variable stress and partial 5-HT denervation by parachloroamphetamine treatment in the rat: effects on behavior and monoamine neurochemistry. Brain Res 2001, 899:227-239.

66. Porsolt R, Papp M: CNS - Psychiatric models of disease: depression. In Current Protocols in Pharmacology. Edited by Williams M, Enna SJ, Kenakin T, Ferkany JW. New York: Wiley; 1998:591-598.

67. Bouwer $\mathrm{CD}$, Harvey BH: Phasic craving for carbohydrate observed with citalopram. Int Clin Psychopharmacol 1996, 11:273-278.

68. Dikkes $P$, Hawkes $C$, Kar S, Lopez MF: Effect of kainic acid treatment on insulin-like growth factor- 2 receptors in the IGF2-deficient adult mouse brain. Brain Res 2007, 1131:77-87.

69. Boksa P, Zhang Y, Amritraj A, Kar S: Birth insults involving hypoxia produce long-term increases in hippocampal [125I]insulin-like growth factor-I and -II receptor binding in the rat. Neuroscience 2006, 139:451-462

70. Mackay KB, Loddick SA, Naeve GS, Vana AM, Verge GM, Foster AC: Neuroprotective effects of insulin-like growth factor-binding protein ligand inhibitors in vitro and in vivo. J Cereb Blood Flow Metab 2003, 23:1160-1167.

71. Beggel S, Connon R, Werner I, Geist J: Changes in gene transcription and whole organism responses in larval fathead minnow (Pimephales promelas) following short-term exposure to the synthetic pyrethroid bifenthrin. Aquat Toxicol 2011, 105:180-188.
72. Agis-Balboa RC, Arcos-Diaz D, Wittnam J, Govindarajan N, Blom K, Burkhardt S, Haladyniak U, Agbemenyah HY, Zovoilis A, Salinas-Riester G, et al: A hippocampal insulin-growth factor 2 pathway regulates the extinction of fear memories. EMBO J 2011, 30:4071-4083.

73. Bracko O, Singer T, Aigner S, Knobloch M, Winner B, Ray J, Clemenson GD Jr, Suh H, Couillard-Despres S, Aigner L, Gage FH, Jessberger S: Gene expression profiling of neural stem cells and their neuronal progeny reveals IGF2 as a regulator of adult hippocampal neurogenesis. J Neurosci 2012, 32:3376-3387.

74. Castren E, Rantamaki T: The role of BDNF and its receptors in depression and antidepressant drug action: reactivation of developmental plasticity. Dev Neurobiol 2010, 70:289-297.

75. Mellott TJ, Follettie MT, DiesI V, Hill AA, Lopez-Coviella I, Blusztajn JK: Prenatal choline availability modulates hippocampal and cerebral cortical gene expression. FASEB J 2007, 21:1311-1323.

76. Hawkes C, Kar S: Insulin-like growth factor-II/mannose-6-phosphate receptor: widespread distribution in neurons of the central nervous system including those expressing cholinergic phenotype. J Comp Neurol 2003, 458:113-127.

77. Chen DY, Stern SA, Garcia-Osta A, Saunier-Rebori B, Pollonini G, BambahMukku D, Blitzer RD, Alberini CM: A critical role for IGF-II in memory consolidation and enhancement. Nature 2011, 469:491-497.

78. Jang SW, Liu X, Pradoldej S, Tosini G, Chang Q, luvone PM, Ye K: $\mathrm{N}$-acetylserotonin activates TrkB receptor in a circadian rhythm. Proc Natl Acad Sci USA 2010, 107:3876-3881

79. Viikki M, Anttila S, Kampman O, Illi A, Huuhka M, Setala-Soikkeli E, Mononen $\mathrm{N}$, Lehtimaki T, Leinonen E: Vascular endothelial growth factor (VEGF) polymorphism is associated with treatment resistant depression. Neurosci Lett 2010, 477:105-108

80. Amritraj A, Rauw G, Baker GB, Kar S: Leu27 insulin-like growth factor-II, an insulin-like growth factor-II analog, attenuates depolarization-evoked GABA release from adult rat hippocampal and cortical slices. Neuroscience 2010, 170:722-730.

81. Hawkes C, Jhamandas JH, Harris KH, Fu W, MacDonald RG, Kar S: Single transmembrane domain insulin-like growth factor-II/mannose-6phosphate receptor regulates central cholinergic function by activating a G-protein-sensitive, protein kinase C-dependent pathway. J NeurosC 2006, 26:585-596.

82. Kapadia R, Yi JH, Vemuganti R: Mechanisms of anti-inflammatory and neuroprotective actions of PPAR-gamma agonists. Front Biosci 2008, 13:1813-1826

83. Jiang Y, Deacon R, Anthony DC, Campbell SJ: Inhibition of peripheral TNF can block the malaise associated with CNS inflammatory diseases. Neurobiol Dis 2008, 32:125-132.

84. Campbell SJ, Deacon RM, Jiang Y, Ferrari C, Pitossi FJ, Anthony DC: Overexpression of IL-1beta by adenoviral-mediated gene transfer in the rat brain causes a prolonged hepatic chemokine response, axonal injury and the suppression of spontaneous behaviour. Neurobiol Dis 2007 27:151-163.

\section{doi:10.1186/1471-2202-13-110}

Cite this article as: Cline et al:: The neuronal insulin sensitizer dicholine succinate reduces stress-induced depressive traits and memory deficit: possible role of insulin-like growth factor 2. BMC Neuroscience 2012 $13: 110$

\section{Submit your next manuscript to BioMed Central and take full advantage of:}

- Convenient online submission

- Thorough peer review

- No space constraints or color figure charges

- Immediate publication on acceptance

- Inclusion in PubMed, CAS, Scopus and Google Scholar

- Research which is freely available for redistribution 